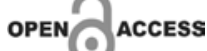

\section{ATUALIZAÇÃO DE TEMA}

\title{
Uso de Células Tronco Mesenquimais na Medicina Regenerativa e Rejuvenescimento
}

\author{
Mesenchymal Stem Cells in Regenerative Medicine \\ and Rejuvenation
}

\author{
André Ney Menezes Freire ${ }^{1,2^{*}}$, Mateus Dantas Moraes Freire ${ }^{3}$, José Válber Meneses \\ Lima $^{1}$, Roberto Jose Batista Dorea ${ }^{4}$, Alex Guedes ${ }^{2,5}$, Tercio Rocha ${ }^{6}$, Maria Luiza \\ Silva $^{3}$, Songeli Menezes Freire ${ }^{7}$, Ricardo Ribeiro dos Santos ${ }^{8}$ \\ ${ }^{1}$ Professor Titular da UFBA; ${ }^{2}$ Médico do Hospital Santa Izabel; ${ }^{3}$ Acadêmico de Medicina \\ (FTC); ${ }^{4}$ Médico Ortopedista da Clínica de Terapia Articular (CTA); ${ }^{5}$ Professor Associado \\ 1 do Departamento de Cirurgia Experimental e Especialidades Cirúrgicas da UFBA; \\ ${ }^{6}$ Médico Endocrinologista; ${ }^{7}$ Professora do Instituto de Ciências da Saúde da UFBA; \\ ${ }^{8}$ Professor Titular de Instituto de Tecnologia em Saúde do Senai / Cimatec e Pesquisador \\ Emérito da FIOCRUZ Ba; Salvador, Bahia, Brazil
}

Correspondence addresses: Dr. André Ney Menezes Freire andreney.freire@gmail.com

Received: April 11, 2021

Revised: May 24, 2021

Accepted: June 10, 2021

Published: June 30, 2021

Data Availability Statement: All relevant data are within the paper and its Supporting Information files.

Funding: This work was the result of authors' initiative. There was no support of research or publication funds.

Competing interests: The authors have declared that no competing interests exist.

Copyright

(C) 2021 by Santa Casa

de Misericórdia da Bahia.

All rights reserved.

ISSN: 2526-5563

DOI: 10.35753
O uso das células-tronco mesenquimais é um passo que a medicina regenerativa dá na direção da recuperação parcial ou total de algumas lesões, além da capacidade de trazer de volta funções perdidas com a idade. Com esse objetivo são utilizadas diversas técnicas com uma variedade de bioprodutos como o plasma rico em plaquetas (PRP), plasma rico em fibrinas (PRF) e fração vascular estromal. As células-tronco mesenquimais são usadas em pesquisas e aplicadas para melhorar e ou devolver capacidades funcionais ou estéticas aos pacientes. Mesmo essas terapêuticas estando em desenvolvimento, já se pode observar resultados promissores em diversas áreas, como da cirurgia plástica, ortopedia, cardiologia e neurologia, dentre tantas outras. Contudo, percebe-se que as respostas dos pacientes variam dependendo de fatores individuais, sendo necessário compreender os mecanismos envolvidos e a necessidade de cada paciente. Dessa forma, a Medicina Regenerativa é capaz de recuperar lesões que anteriormente seriam consideradas irrecuperáveis, o que permite o alívio da dor física e do sofrimento psíquico de diversas pessoas acometidas por doenças crônicas e deformidades.

Palavras-chave: Plasma Rico em Plaquetas; Plasma Rico em Fibrina; Fibrina; Células-Tronco; Medicina Regenerativa; Rejuvenescimento.

Mesenchymal stem cells are part of regenerative medicine that could recover disabilities, in addition to the ability to restore functions lost with age. For this purpose, there are several techniques with many bioproducts as platelet-rich plasma (PRP), fibrin-rich plasma (PRF), and stromal vascular fraction. Mesenchymal stem cells are used in research and applied to improve and/or return function or aesthetics to patients. Even with these early therapies in development, it is already possible to observe several promising results in many areas, such as plastic surgery, orthopedics, cardiology, and neurology, among many others. However, the patients' responses varied according to individual factors, making it necessary to understand the mechanism according to the needs of each patient. Thus, we conclude that Regenerative Medicine can recover lesions that were previously considered irrecoverable. And it might allow the relief of physical pain and psychological suffering of many people affected by chronic diseases and deformities. 
Keywords: Platelet Rich Plasma; Fibrin-Rich Plasma; Fibrin; Stem cells; Regenerative Medicine; Rejuvenation.

Destaques - Highlights

* O PRP é fonte de matriz com fatores e plaquetas contendo organelas e capacidade biológica interessante para o estímulo celular. E pode ser obtido pela centrifugação do sangue colocado em um tubo com anticoagulantes.

* PRP mostra alto potencial de viabilidade celular de células-tronco mesenquimais humanas.

* O PRF é fonte de biomoléculas capazes de estimular funções celulares e teciduais. E pode ser obtido pela centrifugação do sangue colocado em um tubo sem anticoagulantes.

* $O$ PRF pode atuar como arcabouço bioativo na medicina regenerativa.

* A fração vascular estromal é uma população de células heterogêneas vinda do tecido adiposo que contém altas taxas de células-tronco mesenquimais. E pode ser obtida pela centrifugação do lipoaspirado.

* As células-tronco mesenquimais são células adultas multipotentes, que têm a função de reparo e reposição tecidual.

* O sucesso das estratégias de medicina regenerativa depende da proposta do tratamento e abordagem, caso a caso.

* A estética pode auxiliar no estabelecimento positivo da autoestima e no contexto geral, pode-se abordá-la no âmbito da medicina estética, importante área atual da saúde, uma vez que esta não engloba apenas ausência de doenças fisicas ou psíquicas, mas também o bem-estar como um todo.

*Considerando uma corrente diferente que pode ser usada de forma convergente à medicina curativa, na prática da medicina estética recentemente registou-se um aumento de interesse e ofertas de serviços, com um alto número de produtos e protocolos inovadores aprovados pela ANVISA no Brasil.

* Atualmente há um aumento do número de clínicas com protocolos para desenvolver e aplicar produtos injetáveis de concentrado em bioprodutos autólogos como PRP e PRF, fração estromal de lipoaspiração contendo quantidades de plaquetas e / ou fibrina elou fatores de crescimento, para estimular a reparação de tecidos e o rejuvenescimento da pele.

*Associados aos protocolos para a aquisição e inoculação de bioprodutos autólogos/autógenos, encontra-se também uma nova variedade com resgate de compostos e medicamentos lançados para diferentes fins já testados, que têm sido aplicados para alcançar os objetivos de reparo, substituição, regeneração nas áreas da medicina regenerativa e da medicina estética.

* Rejuvenescimento é umprocesso de tratamento de prevenção, promoção da saúde para tornar-se jovem ou tornar jovem novamente. Ou ainda procedimento que evita, retarda, corrige, interrompe o processo de envelhecimento, caracterizado pela perda de função da pele e tecido de sustentação, perda do brilho e da elasticidade da pele, queda dos tecidos, músculos e gordura, podendo causar flacidez, linhas de expressão e rugas.

* Abordagens terapêuticas estéticas de rejuvenescimento podem incluir transplante, engenharia de tecidos, terapia celular e terapia genética. Todos eles podem usar adicionalmente materiais preparados exogenamente (ex vivo) para modular a força do tecido ou órgão a ser reparado, regenerado.

\section{Introdução}

O ser humano sempre buscou a imortalidade. Apesar de estarem longe desse feito, médicos e demais profissionais, cientistas e pesquisadores das áreas da saúde e das áreas biológicas debruçam-se em intensos estudos a respeito das células-tronco, quedetêm o poder de especializarse, diferenciar-se, em qualquer novo tecido, desde que estimulada para sofrer tal alteração.

Entretanto, esse conhecimento possui custos elevadíssimos, não somente financeiros, mas sobretudo sociais. Afinal, entram nesse campo os princípios que norteiam a vida em diversas sociedades, a saber: a ética e a moral.

A despeito de inúmeras sociedades aceitarem estudos amplos sobre as células-tronco, aqui no Brasil existe regulamentação própria sobre sua utilização na Medicina, sendo permitido o uso experimental e em algumas situações específicas. Podem, no entanto, ser utilizadas em um vasto campo de tratamento, como o proposto para regenerar tecidos que envelhecem e em estruturas que estão fadadas à morte por doenças irrecuperáveis, lesões traumáticas, vasculares e degenerativas, possibilitando assim que muitas 
pessoas possam se beneficiar dessa rica terapia moderna.

Rejuvenescer é tornar jovem novamente: dar novo vigor a, e restaurar a um estado original ou novo, ${ }^{1,2}$ sendo este um dos objetivos da Medicina Regenerativa. Nela há um campo interdisciplinar de pesquisa e aplicações clínicas focadas no reparo, substituição ou regeneração de células, tecidos ou órgãos para restaurar a função prejudicada resultante de qualquer causa, além de defeitos congênitos. São usadas combinações de abordagens tecnológicas convergentes, existentes e emergentes, que vão além do transplante tradicional e das terapias de substituição. $^{2}$

Para a aplicação dela temos visto um desenvolvimento no campo da Engenharia de Tecidos. Essa área, como é conhecida hoje, teve sua definição em 1987 como sendo "a aplicação dos princípios e métodos de engenharia e das ciências biológicas para a compreensão fundamental das relações estrutura-função no tecido normal e patológico de mamíferos e o desenvolvimento de substitutos biológicos para restaurar, manter ou melhorar a função". ${ }^{3}$

Neste artigo, resgatamos temas de interesse na abordagem contemporânea de células tronco mesenquimais presentes nos diferentes bioprodutos em procedimentos propostos na Medicina Regenerativa.

\section{Medicina Regenerativa, Engenharia Tecidual, Recuperação do Estado de Saúde}

Passados quase 20 anos de estudos sobre células-tronco, acompanhou-se o desenvolvimento da engenharia tecidual, da biologia celular e das ferramentas, equipamentos e protocolos de biotecnológicos incrementandose a abrangência da terapêutica médica, que hoje está intimamente ligada à Medicina Regenerativa.

Os processos inflamatórios variam conforme as características do fator causal e do tecido/órgão envolvidos, seja por agente infeccioso ou não, por processo degenerativo, desgaste orgânico decorrente do avanço do relógio biológico ou senescência. Com as propostas corretas e tratamentos adequados pode-se recuperar/ restaurar/restabelecer total ou parcialmente a função perdida.

$\mathrm{Na}$ terapêutica anatomofisiológica ou simplesmente estética, para a aplicação dos diversos métodos da Medicina Regenerativa, deve-se então compreender o problema e as estruturas do tecido/órgão a ser regenerado, desde a composição celular que define a estrutura tecidual, junto ao espaço intersticial, matriz extracelular, pelas diferentes funções celulares e moleculares, controladas genética ou endocrinamente nas diferentes correlações entre os sistemas do corpo.

Deve-se observar e conhecer intimamente o parênquima composto de células responsáveis pela função típica do órgão, tecido específico funcional, assim como o seu estroma, componentes do tecido de sustentação, incluindo a celularidade complexa conjuntiva e os vasos sanguíneos.

A proposta do método e do protocolo a ser empregado varia com as condições do usuário do serviço, da especialidade médica que oferece as diversas possibilidades técnicas, e do avanço tecnológico do centro de terapia celular. Devese sempre buscar o foco do procedimento nas atividades da Medicina Regenerativa (Figura 1).

\section{Marcos Técnicos e Legais da Medicina Regenerativa no Brasil}

No Brasil, desde 2005, o Ministério da Saúde reforça a importância da política de inovações tecnológicas na atenção à saúde, com a publicação da PORTARIA N ${ }^{\circ}$ 2.510, DE 19 DE DEZEMBRO DE 2005, quando instituiu a Comissão para Elaboração da Política de Gestão Tecnológica no âmbito do Sistema Único de Saúde - CPGT, estabelecendo no Art $3^{\circ}$ que à Comissão para Elaboração da Política de Gestão 
Figura 1. Atividades da Medicina Regenerativa.

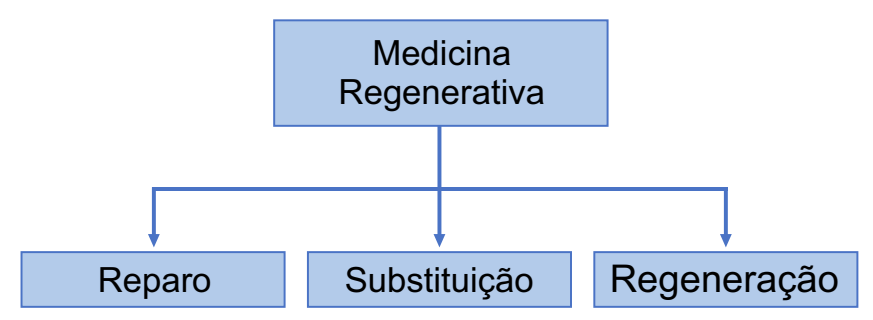

Tecnológica compete elaborar proposta para a política de gestão de tecnologias no SUS. ${ }^{4}$

Em 2011, a ANVISA através da Resolução $\mathrm{N}^{\circ}$ 9, DE 14 DE MARÇO DE 2011 dispõe sobre o funcionamento dos Centros de Tecnologia Celular para fins de pesquisa clínica e terapia e dá outras providências, alertando para as considerações, cuidados e protocolos exigidos. E traz diversas definições legais e técnicas de interesse a abordagem deste artigo, aqui transcritas, tais como:

"VII - Biossegurança: condição de segurança alcançada por um conjunto de ações destinadas a prevenir, controlar, reduzir ou eliminar riscos inerentes às atividades que possam comprometer a saúde humana, animal e o meio ambiente;

$X$-Células-tronco humanas: célula de origem humana que possuem a capacidade de se autorenovar por longos periodos de tempo e de se diferenciar ao receber estímulos especificos; $X I$ - Células-tronco adultas (CTA): células tronco originadas a partir de diferentes órgãos e tecidos, depois do nascimento do indivíduo (post partum), incluindo os anexos extra-embrionários (placenta e cordão umbilical);

XIII - Células-tronco pluripotentes induzidas (CTPi): células criadas a partir de reprogramação de células somáticas, de CTA ou de qualquer outro tipo de célula humana;

$X I V$ - Centros de Tecnologia Celular (CTC): serviço que, com instalações físicas, recursos humanos, equipamentos, materiais, reagentes e produtos para diagnóstico de uso in vitro e metodologias, realiza atividades voltadas à utilização de células humanas, inclusive seus derivados, em pesquisa clínica elou terapia."
Nesta RDC N.9 de 2011 da ANVISA, considerase dentro das Boas Práticas de Fabricação (BPF), a Garantia e Gestão de Qualidade, Gestão Ambiental, Biossegurança, Qualificação de Equipamentos, Validação, Rastreabilidade de todos os materiais e reagentes, Rastreabilidade dos produtos, considerando-se os Procedimentos Operacionais Padrão (POP) para todos os procedimentos, incluindo: coleta, processamento, acondicionamento, armazenamento, controle de qualidade, liberação para uso, transporte e descarte. ${ }^{5}$

\section{Bioprodutos Utilizados na Medicina Regenerativa}

Entre as abordagens usadas na Medicina Regenerativa, algumas se destacam, como o uso de PRP, PRF, a Fração Vascular Estromal e o uso direto de células-tronco. Essas técnicas têm objetivos terapêuticos variados e são usados em diversas áreas das ciências da saúde e na estética atualmente (Figura 2).

\section{Plasma Rico em Plaquetas (PRP)}

O PRP é o plasma autólogo contendo alta concentração plaquetária ${ }^{6}$ e apresenta cerca de $0,7 \%$ de células-tronco em sua composição celular. O potencial terapêutico das plaquetas é baseado em seu rico complemento de fatores de crescimento anabólico e citocinas antiinflamatórias nas plaquetas, que induzem proliferação celular, migração, diferenciação, angiogênese e síntese de matriz extracelular (MEC) ${ }^{6}$ O efeito positivo na cicatrização de tecido é obtido com um alto suprimento de plaquetas e 
Figura 2. Bioprodutos e técnicas utilizadas na medicina regenerativa e na Medicina Estética.

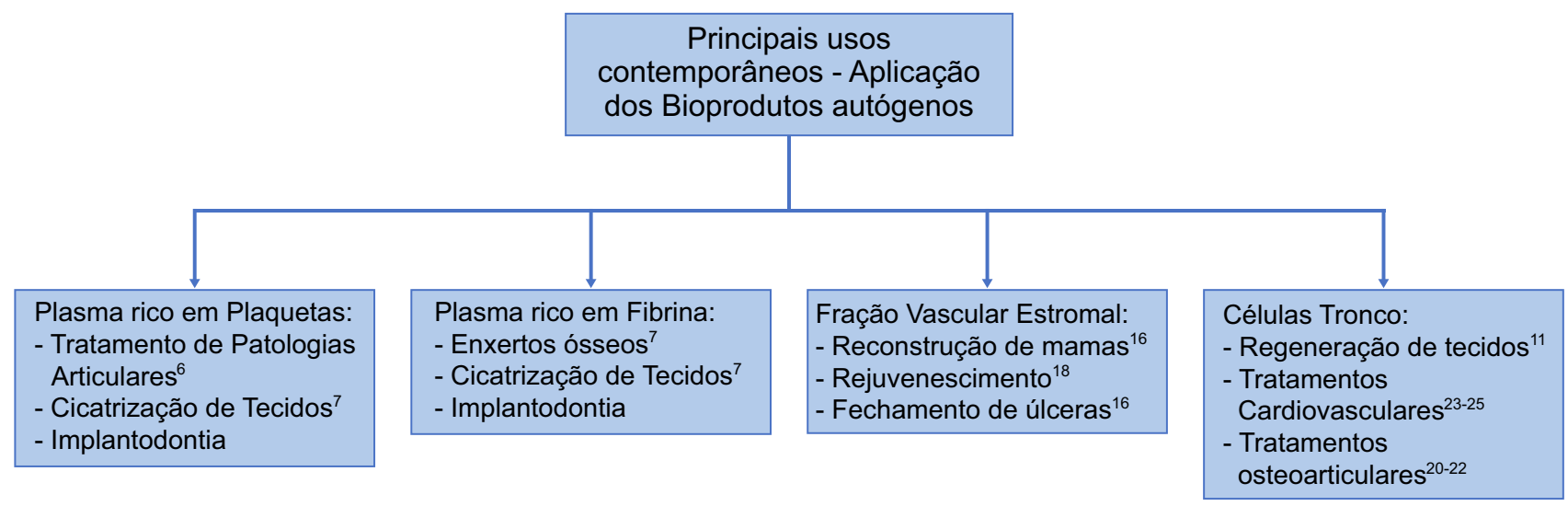

leucócitos na preparação. ${ }^{6}$ As plaquetas contêm três tipos de grânulos: grânulos $\alpha$, grânulos densos e grânulos lisossomais. Os grânulos alfa são uma fonte de fatores de crescimento, incluindo fatores de crescimento derivados de plaquetas (PDGF), fator de crescimento semelhante à insulina-1 (IGF-1), fator de crescimento endotelial vascular (VEGF), fator de crescimento transformador (TGF). ${ }^{6}$ O principal papel dos fatores de crescimento contidos no PRP é recrutar e ativar outras células do sistema imunológico ou induzir a inflamação das células endoteliais. Outros fatores presentes nos grânulos $\alpha$ são quimiocinas e citocinas, como o fator plaquetário 4 (PF4), proteína básica pró-plaquetária e P-selectina, envolvidos na estimulação da quimiotaxia celular, proliferação e maturação, bem como na modulação de moléculas inflamatórias. Os grânulos densos contêm ADP, ATP, serotonina, dopamina, polifosfatos, histamina e epinefrina que modificam a ativação plaquetária e a formação de trombos. Muitos desses elementos têm efeitos modificadores das células imunológicas.

A histamina e a serotonina aumentam a permeabilidade dos capilares, possibilitando a migração de células envolvidas no processo inflamatório, como os macrófagos, e estimulam fibroblastos, células-tronco mesenquimais e condrócitos autólogos. Os grânulos lisossomais contêm hidrolases, catepsina D e E, elastase e lisozima, e muitas outras proteínas cujo papel fisiológico não foi bem caracterizado até agora. ${ }^{6}$

\section{Plasma Rico em Fibrina (PRF)}

O PRF é um biomaterial, também autólogo, de baixo custo e fácil obtenção, representa a segunda geração dos chamados agregados plaquetários. Assim como o PRP, o PRF também apresenta em sua composição celular cerca de $0,7 \%$ de células-tronco.

Como uma membrana de fibrina, rica em leucócitos, plaquetas e fatores de crescimento, é obtido, a partir do sangue que passa por um processo de enriquecimento, preferencialmente em centrífuga com rotor swing. ${ }^{7}$ Esse biomaterial contém plaquetas, leucócitos, citocinas, fatores de crescimento e células-tronco circulantes. Após sua obtenção, ele pode ser utilizado em sua forma líquida ou aglutinado a enxertos ósseos, como a hidroxiapatita. ${ }^{7}$ Com o processo de coagulação, o PRF forma uma consistência de gel, segurando consigo o enxerto ósseo. ${ }^{7}$ Além disso, a liberação de fatores de crescimento é benéfica ao enxerto, proporcionando uma cicatrização óssea satisfatória, além de favorecer uma melhora do reparo tecidual. ${ }^{7}$

\section{Células-Tronco}

As células tronco são células indiferenciadas presentes em organismos multicelulares. ${ }^{8}$ Essas células primárias são capazes de se dividir e permanecem não especializadas por um período de tempo relativamente longo. ${ }^{8}$ Então, quando os 
sinais necessários estiverem presentes, o processo de replicação constante, chamado de proliferação, é acionado. ${ }^{8}$ Geralmente, as células-tronco podem produzir milhões de células quando cultivadas corretamente em laboratório. ${ }^{8}$

Essas células são indispensáveis para a manutenção de muitos tecidos adultos e sustentam os tecidos por conta de duas propriedades principais: capacidade de auto renovação, pela qual podem proliferar, e sua capacidade de produzir células-filhas em processo de diferenciação, que substituem células mortas em tecidos com alta taxa de renovação celular. ${ }^{9}$ Para manter a homeostase dos tecidos é necessário que tenha uma regulação precisa do equilíbrio entre a auto renovação e a diferenciação dessas células. ${ }^{9}$ Além disso, as células tronco possuem plasticidade para lidar com o estresse, insultos e lesões que atingem os tecidos. ${ }^{9}$ As células-tronco apresentam uma plasticidade que as permite alterarem sua atividade, quando usadas na reparação e modulação da função de um tecido. ${ }^{9}$ Geralmente, as células-tronco ficam em "nichos", microambientes especializados que regulam tanto a auto renovação quanto a diferenciação e que respondem a alterações ambientais e fisiológicas. ${ }^{9}$ As células-tronco podem ser embrionárias, ou adultas, extraídas dos diversos tecidos humanos, tais como, medula óssea, sangue, fígado, cordão umbilical, placenta, dentre outros. ${ }^{8}$

Normalmente, embriões pré-implantados, cinco dias após a fecundação, os chamados blastocistos, são considerados as melhores fontes de células-tronco. ${ }^{8}$ Embora outras fontes também sejam conhecidas, as células-tronco de blastocistos têm o potencial único de se diferenciar em todas as linhagens celulares. ${ }^{8}$ Além disso, os blastocistos podem ser facilmente cultivados in vitro para produzir as células-tronco que são relativamente fáceis de coletar, purificar e gerenciar para finalidades científicas. ${ }^{8}$ Entretanto, no Brasil, não é permitido o uso de embriões para manipulação para obtenção de células-tronco.

$\mathrm{O}$ sangue do cordão umbilical é rico em células-tronco. ${ }^{8}$ Embora as células-tronco mais versáteis sejam obtidas a partir de embriões, as células-tronco derivadas do cordão umbilical são capazes de formar um número relativamente satisfatório de tipos de células especializadas. ${ }^{8}$ Além disso, o fato de que as células-tronco do cordão umbilical podem ser uma alternativa "ética" ao uso de embriões como fontes de células tronco mostra sua atual importância médica. ${ }^{8}$

Células-tronco somáticas ou células-tronco adultas são células que sofreram diferenciação parcial, mas não total. ${ }^{8}$ Por exemplo, as células-tronco do sistema nervoso só podem se diferenciar em células encontradas nos tecidos cerebrais, mas não em células estranhas ao cérebro, como as células do pâncreas. ${ }^{8}$ As células-tronco adultas estão apenas em órgãos específicos, principalmente aqueles que passam por constantes substituições celulares devido à exaustão química ou mecânica. ${ }^{8}$

Ademais, existem também as células mesenquimais, que são células-tronco adultas multipotentes, encontradas em vários tecidos, incluindo medula óssea, cordão umbilical e tecido adiposo. Sua função no organismo é de reparação e reposição de tecidos e tem um limite na sua capacidade de diferenciação. Mas, dependendo do estímulo, elas podem se diferenciar em múltiplos tecidos, como o tecido adiposo, ósseo e cartilaginoso, apresentando um potencial para tratamento de doenças que acometem esses tecidos. ${ }^{10}$

Além disso, as células mesenquimais desempenham um papel importante na homeostase agindo diretamente na regeneração do tecido, cicatrização de feridas, comunicação intercelular e imunomodulação. ${ }^{11}$ Elas têm sido amplamente estudadas por conta das possibilidades clínicas na terapia com célulastronco devido à sua capacidade anti-inflamatória e regenerativa de tecidos (Figura 3). ${ }^{11}$

\section{Fração Vascular Estromal (FVE)}

O estroma é definido como tecido conjuntivo vascularizado que forma o tecido nutritivo e 
Figura 3. Células-tronco mesenquimais e seu potencial de diferenciação.

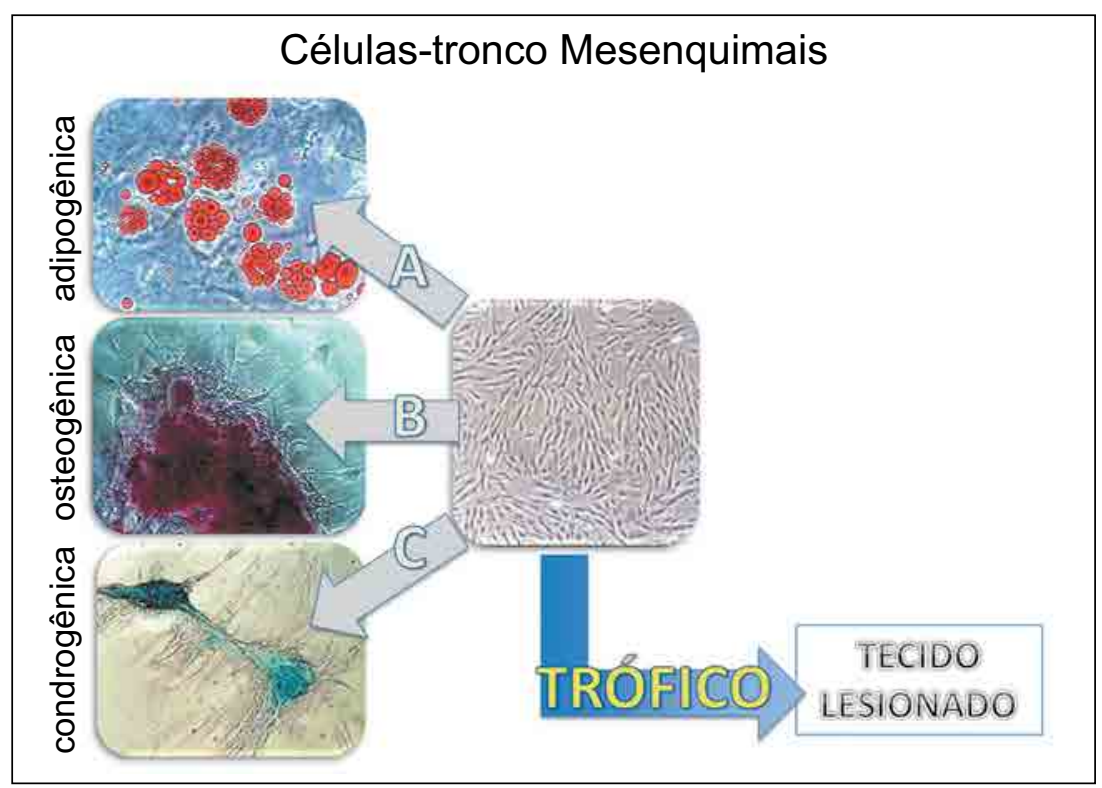

Fonte: Imagem fornecida pelo Professor Ricardo Ribeiro dos Santos.

de sustentação de um órgão, glândula ou de estruturas patológicas, como os tumores.

Já a fração vascular estromal (FVE) consiste de uma população heterogênea de células mesenquimais que são obtidas do tecido adiposo por um processo de centrifugação. A FVE chega a apresentar em torno de $25 \%$ de células-tronco.

A composição não inclui apenas células estromais adiposas e hematopoiéticas e progenitoras, mas também células endoteliais, eritrócitos, fibroblastos, linfócitos, monócitos / macrófagos e pericitos, dentre outros. ${ }^{12}$

Tecnicamente, os processos usados para obtenção dessas células são chamados de manipulação mínima, que abrange o processamento de material biológico que não altera de maneira relevante as características originais, como separar células, centrifugar, purificar, filtrar, criopreservar. ${ }^{13}$

Para obter a FVE 1 pode-se usar uma cânula ligada a uma bomba que gera pressão negativa. $\mathrm{O}$ aspirado de gordura obtido pela lipoaspiração deve então ser centrifugado, o que gera 3 fases e a fração do meio contém as células mesenquimais. Mas a quantidade de células obtidas varia dependendo do indivíduo. ${ }^{13}$

O tecido adiposo contém 100-1.000 vezes mais células-tronco mesenquimais do que a medula óssea, isso juntamente com o fato da sua coleta ser muito menos dolorosa do que a da medula, o que faz com que o uso clínico da FVE tenha se ampliado consideravelmente nos últimos anos. Além disso, pode ser preparada de forma simples, a partir de um volume relativamente pequeno de lipoaspirado, com treinamento mínimo, utilizando protocolos manuais ou automáticos e seguindo protocolos comerciais. ${ }^{14}$

\section{Aspectos Técnico-Científicos dos Bioprodutos Autólogos}

O Quadro 1 apresenta alguns pontos principais de etapas da cicatrização de feridas e seus fatores de crescimento associados considerando $o$ reparo, a substituição e a regeneração.

O principal papel dos fatores e citocinas contidos nos bioprodutos como o PRP tem sido associado com as funções de recrutar $\mathrm{e}$ ativar células do sistema de defesa e modulam a inflamação interferindo nas células do tecido 
conjuntivo e endoteliais. Os diversos fatores de crescimento e citocinas produzidos em plaquetas e outras células foram revisados recentemente e sua aplicação em osteoartrite de joelho demonstrou achados positivos na modulação estrutural e efeito anti-inflamatório na articulação do joelho. ${ }^{6}$

Pode-se observar que da totalidade dos fatores descritos anteriormente em modelo de análise de reparo tecidual descrito por Krafts em 2010, ${ }^{15}$ vários fatores e citocinas adicionais produzidas por células presentes no PRP estão presentes (Quadro 2).

\section{Aplicações da Medicina Regenerativa}

Recentemente, um número crescente de artigos vem demonstrando o uso de fração vascular estromal suplementando enxertos de gordura para diversas aplicações, como reconstrução de mamas, cicatrização, reparo de úlceras e aumento das mamas. ${ }^{16}$
Em 2008, Youshimura e colaboradores demonstraram sua nova técnica de unir o enxerto de gordura com a fração vascular estromal retirada no mesmo momento do procedimento, através de um processo chamado de Lipo Transferência assistida por células, e observaram um aumento da circunferência mamária com enxertos de gordura centrifugados. ${ }^{17}$

O uso de fração vascular estromal e enxerto de gordura também apresentam bons resultados no rejuvenescimento da face. Foidemonstrado, emum estudo com 16 pacientes que receberam injeções desse material na pálpebra inferior, resultados clínicos classificados como "excepcionais", "muito melhorados" ou "melhorados" em todos os pacientes, com uma pontuação GAIS de média 1,6. Os autores referem que não ocorreram eventos adversos graves, indicando que essa é uma terapia segura e eficaz embora mais estudos sejam necessários para corroborar esses resultados. ${ }^{18}$

Outro potencial campo de aplicação das células tronco é a cicatrização de feridas. A

Quadro 1. Principais etapas na cicatrização de lesão e seus fatores de crescimento associados.

\begin{tabular}{|c|c|c|c|c|c|c|c|c|}
\hline Passos e Fatores & EGF & FGF & KGF & PDGF & TGF-a & TGF- $\beta$ & TNF & VEGF \\
\hline Migração de fibroblastos & & $\mathrm{x}$ & & $\mathrm{x}$ & & $\mathrm{X}$ & & \\
\hline Proliferação de fibroblastos & $\mathrm{x}$ & $\mathrm{x}$ & & $\mathrm{x}$ & $\mathrm{x}$ & & $\mathrm{x}$ & \\
\hline Migração de monócitos & & $\mathrm{x}$ & & $\mathrm{x}$ & & $\mathrm{x}$ & $\mathrm{x}$ & \\
\hline Ativação de macrófagos & & & & & & & $\mathrm{x}$ & \\
\hline Migração epitelial & $\mathrm{x}$ & $\mathrm{x}$ & $\mathrm{x}$ & & $\mathrm{x}$ & & & \\
\hline Proliferação epitelial & $\mathrm{x}$ & $\mathrm{x}$ & $\mathrm{x}$ & & $\mathrm{x}$ & & & \\
\hline Angiogênese & & $\mathrm{x}$ & & $\mathrm{x}$ & $\mathrm{x}$ & & $\mathrm{x}$ & $\mathrm{x}$ \\
\hline Síntese de colágeno & & & & $\mathrm{x}$ & & $\mathrm{x}$ & & \\
\hline Síntese de colagenase & $\mathrm{x}$ & $\mathrm{x}$ & & $\mathrm{x}$ & & & $\mathrm{x}$ & $\mathrm{x}$ \\
\hline Contração da ferida & & $\mathrm{x}$ & & $\mathrm{x}$ & & & & \\
\hline
\end{tabular}


Quadro 2. Fatores de crescimento em plaquetas e sua origem.

\begin{tabular}{|c|c|}
\hline Fatores de Crescimento & Origem \\
\hline TGF- $\beta 1$ & $\begin{array}{l}\text { Plaquetas, linfócitos T, macrófagos / monócitos, neutrófilos, matriz } \\
\text { extracelular do osso, cartilagem, células TH1 ativadas e células natural } \\
\text { killer }\end{array}$ \\
\hline KGF & Plaqueta fibroblasto \\
\hline FGF-1 & Plaqueta macrófago \\
\hline b-FGF ou FGF-2 & Plaquetas, macrófagos, células mesenquimais, condrócitos, osteoblastos \\
\hline VEGF/VEP & Plaquetas, células endoteliais \\
\hline CTGF & $\begin{array}{l}\text { Plaquetas, fibroblastos, células endoteliais, condrócitos, células } \\
\text { musculares lisas }\end{array}$ \\
\hline GM-CDF ou CSFa & $\begin{array}{l}\text { Plaquetas, macrófagos, células } \mathrm{T} \text {, mastócitos, células natural killer, } \\
\text { células endoteliais e fibroblastos }\end{array}$ \\
\hline TNF- $\alpha$ & Plaquetas e células inflamatórias \\
\hline IGF & Plaquetas, osteoblastos, macrófagos, monócitos, condrócitos \\
\hline IL-1 $\beta$ & $\begin{array}{l}\text { Plaquetas ativadas por trombina, células do sistema imunológico inato, } \\
\text { como monócitos e macrófagos }\end{array}$ \\
\hline IL-6 & Plaquetas, osteoblastos, fibroblastos maduros e macrófagos \\
\hline IL-8 & $\begin{array}{l}\text { Plaquetas, macrófagos e outros tipos de células, como células epiteliais, } \\
\text { células do músculo liso das vias aéreas e células endoteliais, monócitos, } \\
\text { neutrófilos e fibroblastos }\end{array}$ \\
\hline PDEGF & Plaquetas, macrófagos, monócitos \\
\hline PDAF & Plaquetas, células endoteliais \\
\hline PF4 & Grânulos alfa de plaquetas ativadas \\
\hline
\end{tabular}

*TGF- $\beta 1$, fator de crescimento transformador beta; KGF, fator de crescimento de queratinócitos; aFGF ou FGF-1, fator de crescimento de fibroblastos ácido; b-FGF ou FGF-2, fator básico de crescimento de fibroblastos; VEGF / VEP, fator de crescimento endotelial vascular; CTGF, fator de crescimento do tecido conjuntivo; GM-CDF ou CSFa, fator estimulador de colônias de granulócitos / macrófagos; TNF- $\alpha$, fator de necrose tumoral; IGF, fator de crescimento semelhante à insulina; IL-1 $\beta$, interleucina 1 $\beta$; IL-6, interleucina 6; IL-8, interleucina 8; PDEGF, fator de crescimento epidérmico derivado de plaquetas; PDAF, fator de angiogênese derivado de plaquetas; PF4, fator plaquetário 4.

Fonte: Traduzido e adaptado de Szwedowski e colaboradores (2021). ${ }^{6}$

aplicação de fração vascular estromal, extraída de um lipoaspirado, em feridas decorrentes de radioterapia mostrou regeneração progressiva da lesão, com formação de neovascularização e melhora da hidratação local. ${ }^{19}$

Ademais, o uso de terapias envolvendo células-tronco e seus derivados no tratamento de doenças neurodegenerativas, como acidentes vasculares, Alzheimer e esclerose múltipla, vem sendo testado com grande potencial. A capacidade de diferenciação e controle parácrino das células-tronco pode ajudar a recuperar áreas de lesão no tecido nervoso afetado por essas patologias. ${ }^{20}$

O tratamento da Diabetes Tipo 1 usando células tronco também está sendo visto com grande expectativa. Após décadas de ensaios clínicos como uso de células-tronco mesenquimais, as terapias de reposição celular estão se tornando uma realidade. Estudos estão mostrando que o transplante de ilhotas humanas em primatas é promissor, com as ilhotas sobrevivendo mais que 800 dias. ${ }^{21}$ 


\section{Medicina Regenerativa na Bahia}

\section{Cirurgia Plástica}

O Cirurgião Plástico, Dr José Valber Lima Menezes da Universidade de Medicina da Bahia e pesquisadores da Faculdade de Medicina da Bahia e do Instituto de Ciências da Saúde da UFBA fizeram um estudo no qual 23 pacientes receberam administrações de células mesenquimais provenientes da medula óssea para o tratamento de úlceras na perna decorrentes de Anemia Falciforme. Entre esses, durante o período de acompanhamento de 6 meses, 91,3\% melhoraram a dor da úlcera em comparação com a linha de base e $29,2 \%$ das úlceras tratadas fecharam-se completamente. Entre os achados, não foi encontrada relação observada entre o resultado do tratamento e o número de células-tronco progenitoras da medula óssea implantadas. $^{22}$

Ortopedia

A terapia com células tronco mesenquimais vem se tornando um procedimento clínico muito aplicado no tratamento de patologias relacionadas com a cartilagem e com o menisco, incluindo a osteoartrite. ${ }^{23}$

Corroborando com isso, o Dr. Roberto Dórea e o Prof. Ricardo Ribeiro dos Santos, fizeram um trabalho que usou o Plasma rico em fatores de crescimento e células mesenquimais para tratar degeneração condral grau IV na articulação do joelho. Nesse estudo, os 3 pacientes tratados tiveram algum grau de regeneração e regressão da lesão de 45 dias a 18 meses depois do tratamento. Com células mesenquimais sendo encontradas nos joelhos e condrócitos novos se desenvolvendo nas áreas de microfratura 40 dias após a aplicação. ${ }^{24}$

Além disso, o Dr. Gildásio Daltro e pesquisadores da Faculdade de Medicina da Bahia e do Instituto de Ciências da Saúde daUFBA desenvolveram pesquisa na remodelação de articulação coxofemoral (quadril) de pacientes com anemia falciforme. Demonstraram que a aplicação de células tronco mesenquimais originárias da medula óssea na cabeça do fêmur de pacientes com Anemia Falciforme que progrediram para osteonecrose da cabeça do fêmur, reduziu significativamente a dor além de cessar a progressão da osteonecrose da cabeça de fêmur em estágios iniciais dos pacientes com Anemia Falciforme. ${ }^{25}$

\section{$\underline{\text { Cardiologia }}$}

Em 2004, o estudo do Professor Ricardo Ribeiro e da Dra. Milena Soares propôs uma "nova estratégia" para reparar ou diminuir os danos causados ao miocárdio de pacientes com chagas crônica cardíaca, através do transplante de células de medula óssea obtidas do próprio indivíduo a ser tratado, proposta anterioremente em estudos para o tratamento de pacientes com insuficiência cardíaca de etiologia isquêmica. O estudo mostra os dados em camundongos sobre "os possíveis efeitos de terapias celulares e sua utilização em pacientes cardiopatas chagásicos crônicos." "26 Apoiando esta teoria, surgiram estudos em modelos animais demonstrando que as células mesenquimais são capazes de fazer imunomodulação. $\mathrm{O}$ que abre caminho para novos tratamentos, podendo ser pelo transplante de células ou pela modificação genética de células de forma que isso aumente a sua ação parácrina, reduzindo a reação imune na Doença de Chagas. ${ }^{27,28}$

O mesmo grupo, juntamente com o Dr. Gilson Soares Feitosa e colaboradores, desenvolveram pesquisa inédita no Brasil em pacientes do Hospital Santa Izabel, demonstrando que a injeção intracoronariana de um aspirado processado da medula óssea promoveu resultados positivos no tratamento de um paciente vítima de insuficiência cardíaca secundária à doença de Chagas. Nesse caso, a fração de ejeção do ventrículo esquerdo (FEVE) em repouso aumentou de $24 \%$ para $32 \%$ depois de 30 dias do procedimento, sem alterar o esquema medicamentoso. Além disso, o 
diâmetro diastólico final do ventrículo esquerdo $(82 \mathrm{~mm} ; 76 \mathrm{~mm})$; escore de qualidade de vida de Minnesota (55; 06); distância caminhada no teste de $6 \min (513 \mathrm{~m} ; 683 \mathrm{~m})$, apresentando a possibilidade de efeitos positivos na prática. ${ }^{29}$

Posteriormente, em 2012, esse mesmo grupo fez um ensaio clínico randomizado com pacientes de 18 a 75 anos apresentando cardiomiopatia chagásica crônica, insuficiência cardíaca classe II a IV (New York Heart Association), FEVE $<35$ e terapia otimizada. Esses pacientes foram randomizados para injeção intracoronária de células mononucleares derivadas da medula óssea autólogas ou placebo. Observou-se que a função ventricular esquerda ou a qualidade de vida em pacientes com cardiomiopatia chagásica crônica não melhoraram com o uso da injeção intracoronária de células mononucleares derivadas da medula óssea autólogas. Contudo, a terapia não apresentou riscos aos pacientes, o que permitiria uma investigação mais aprofundada. ${ }^{30}$

Diante do exposto, os autores deste artigo criaram na na Bahia uma nova equipe de atuação na medicina regenerativa e integrativa, com foco na regeneração celular e de tecidos comprometidos pelo desgaste natural do envelhecimento.

\section{Conclusão}

A aplicação de células-tronco mesenquimais têm grande potencial de uso, tanto como elemento de rejuvenescimento quanto no tratamento de diversas patologias. Mas ainda não é uma terapêutica com protocolos fechados, por isso, torna-se necessário que se formem novos grupos de estudos que ampliem o conhecimento e utilização dessa terapia.

\section{Referências}

1. Kang YJ, Zheng L. Rejuvenation: an integrated approach to regenerative medicine. Regenerative Medicine Research 2013;1(1)

2. Daar AS, Greenwood HL. A proposed definition of regenerative medicine. Journal of Tissue Engineering and Regenerative Medicine 2007;1(3):179-184.
3. Meyer U, Handschel J, Wiesmann HP, Meyer T. Fundamentals of Tissue Engineering and Regenerative Medicine. 1st ed: Springer; 2009. 1049 p. 1 vol. ISBN: 978-3-540-77755-7.

4. Ministério da Saúde (Brasil). Portaria $n^{\circ}$. 2.510, de 19 de dezembro de 2005. Institui Comissão para Elaboração da Política de Gestão Tecnológica no âmbito do Sistema Único de Saúde - CPGT. Diário Oficial da União 19 dez 2005;Seção 1.

5. Ministério da Saúde (Brasil). Resolução $\mathrm{n}^{\circ}$. 9, de 14 de março de 2011. Dispõe sobre o funcionamento dos Centros de Tecnologia Celular para fins de pesquisa clínica e terapia e dá outras providências. Diário Oficial da União 14 mar 2011;Seção 1.

6. Szwedowski D, Szczepanek J, Paczesny L, Zabrzyński J, Gagat M, Mobasheri A, et al. The Effect of PlateletRich Plasma on the Intra-Articular Microenvironment in Knee Osteoarthritis. International Journal of Molecular Sciences 2021;22(11):5492.

7. Lacerda CBV, Silva FBM, Sá JCR, Louro RS, Resende RFB. Plasma rico em fibrina como carreador de biomateriais para reconstrução alveolar após exodontia: relato de caso. Revista Fluminense de Odontologia. 2020;1(53).

8. Herrera SC, Bach EA. The emerging roles of JNK signaling in Drosophila stem cell homeostasis. Int. J. Mol. Sci. 2021;22(11):5519.

9. Aboud L, Anchondo G, Adair A, Zubiate E, Navarro A, Torres R. What are stem cells?. E-Zine Journal 2007.

10. Riquier S, Mathieu M, Bessiere $\mathrm{C}$, Boureux A, Ruffle F, Lemaitre JM, et al. Long non-coding RNA exploration for mesenchymal stem cell characterisation. BMC Genomics 2021;22:412.

11. Yu WD, Kim YJ, Cho MJ, Kim GJ. Kim SH, Kim MJ, et al. MIT-001 Restores human placenta-derived mesenchymal stem cells by enhancing mitochondrial quiescence and cytoskeletal organization. Int. J. Mol. Sci. 2021;22:5062.

12. Bourin P, Bunnell BA, Casteilla L, Dominici M, Katz AJ, March KL, Gimble JM. Stromal cells from the adipose tissue-derived stromal vascular fraction and culture expanded adipose tissue-derived stromal/stem cells: a joint statement of the International Federation for Adipose Therapeutics and Science (IFATS) and the International Society for Cellular Therapy (ISCT). Cytotherapy 2013;15(6):641-648.

13. Tissiani LAL, Aguena M, Passos-Bueno MR, Alonso $\mathrm{N}$. Effects of different liposuction techniques on the isolation of mesenchymal stem cells. Revista Brasileira de Cirurgia Plástica 2012;27:509-513.

14. Andia I, Maffulli N, Burgos-Alonso N. Stromal vascular fraction technologies and clinical applications. Expert Opinion on Biological Therapy 2019; 19(12):1289-1305. 
15. Krafts KP. Tissue repair: The hidden drama. Organogenesis 2010:6(4):225-233.

16. Gentile P, Garcovich S. Systematic review: adipose-derived mesenchymal stem cells, plateletrich plasma and biomaterials as new regenerative strategies in chronic skin wounds and soft tissue defects. International Journal of Molecular Sciences 2021;22(4):1538.

17. Trevor LV, Riches-Suman $\mathrm{K}$, Mahajan AL, Thornton MJ. Adipose tissue: a source of stem cells with potential for regenerative therapies for wound healing. Journal of Clinical Medicine 2020;9(7):2161.

18. Surowiecka A, Piekarski M, Pototschnig H. Stromal vascular fraction and emulsified fat as regenerative tools in rejuvenation of the lower eyelid area. Dermatologic Therapy 2021;34(3):e14937.

19. Rigotti G, Marchi A, Galie M, Baroni G, Benati D, Krampera M, Sbarbati A. Clinical treatment of radiotherapy tissue damage by lipoaspirate transplant: a healing process mediated by adipose-derived adult stem cells. Plastic and Reconstructive Surgery 2007;119(5):1409-1422.

20. Fayazi N, Sheykhhasan M, Asl SS, Najafi R. Stem cell-derived exosomes: A new strategy of neurodegenerative disease treatment. Molecular Neurobiology 2021;58:3494-3514.

21. Klerk E, Hebrok M. Stem cell-based clinical trials for Diabetes Mellitus. Front Endocrinol. 2021;12: 631463.

22. Meneses JVL, Fortuna V, Souza ES, Daltro GC, Meyer $\mathrm{R}$, Minniti CP, et al. Autologous stem cell-based therapy for sickle cell leg ulcer: a pilot study. British Journal of Haematology 2016;175(5):949-955.

23. Ozeki N, Nakagawa Y, Mizuno M, Kohno Y, Katano H, Koga H, \& Sekiya I. Ultrasound-guided harvesting of synovium for regenerative medicine of cartilage and meniscus using synovial mesenchymal stem cells. Arthroscopy Techniques Jun 2021.
24. Dórea RJB, Noronha JCPP, Santos RR, Sodré FL. Articular hyaline cartilage injury with plasma rich in growth factors and stem cell. Clínica de Terapia Articular, BA.

25. Daltro GC, Fortuna V, Souza ES, Salles MM, Carreira AC, Meyer R, Borojevic R, Freire SM. Efficacy of autologous stem cell-based therapy for osteonecrosis of the femoral head in sickle cell disease: a five-year follow-up study. Stem Cell Tesearch \& Therapy 2015:6(1):1-18.

26. Santos RR, Soares MBP, Carvalho ACC. Bone marrow cells transplant in the treatment of chronic chagasic cardiomyopathy. Revista da Sociedade Brasileira de Medicina Tropical 2004;37(6):490-495.

27. Silva DN, Souza BSF, Vasconcelos JF, Azevedo CM, Valim CXR, Paredes BD. Granulocyte-colony stimulating factor-overexpressing mesenchymal stem cells exhibit enhanced immunomodulatory actions through the recruitment of suppressor cells in experimental Chagas Disease cardiomyopathy.Front. Immunol. 2018 Jun.

28. Silva D N, Souza, BSF, Azevedo CM, Vasconcelos JF, Carvalho RH, Soares MBP, Santos RR. Intramyocardial transplantation of cardiac mesenchymal stem cells reduces myocarditis in a model of chronic Chagas disease cardiomyopathy. Stem Cell Research \& Therapy 2014:5(4):1-10.

29. Fábio VB, Feitosa GS, Soares MBP, Pinho JA, Mota A, Almeida AJG. Transplante de células de medula óssea para o miocárdio em paciente com insuficiência cardíaca secundária à doença de Chagas. Arquivo Brasileiro de Cardiologia 2004;82(2).

30. Santos, RR, Rassi S, Feitosa G, Grecco OT, Rassi JrA, Cunha AB, Carvalho ACC. Cell Therapy in Chagas cardiomyopathy (Chagas arm of the multicenter randomized trial of cell therapy in cardiopathies study). A multicenter randomized trial. Circulation 2012;125(20):2454-2461. 